\title{
1 Los estudios críticos del discurso
}

Los estudios críticos del discurso (a partir de aquí ECD) son un enfoque interdisciplinario que busca explicar la manera en que el discurso afecta los procesos, las estructuras y los cambios sociales (Flowerdew \& Richardson 2018, p. 1). Más específicamente, los ECD son un tipo de análisis discursivo que estudia cómo la ideología, la identidad y las inequidades son (re)creadas mediante textos producidos en contextos sociales y políticos (van Dijk 2001, p. 352). Esta perspectiva concibe el discurso como una forma de práctica social, por lo que se concentra en el análisis del lenguaje en sus contextos de uso (Fairclough 1989; Wodak \& Meyer 2016) y tiene como objetivo entender, exponer y resistir las ideologías que fomentan la inequidad y la injusticia social. En justamente este objetivo el que hace que se le califique con el término "crítico", pues los ECD representan un enfoque comprometido socialmente que busca lograr el cambio social, o al menos, apoyar la lucha contra la desigualdad (van Dijk 2001).

Los estudios críticos del discurso se desarrollan históricamente a partir de la lingüística crítica (cfr. Fowler et al. 1979; Kress 1989), una aproximación lingüística cuyo objetivo era el de develar el rol de la ideología y el poder en la práctica de la lengua en uso y la capacidad persuasiva de ciertas formas sintácticas (Flowerdew \& Richardson 2018, p. 1). Posteriormente, en los años noventa, este enfoque fue conocido como análisis crítico del discurso (ACD) y llevado a la práctica por autores como Norman Fairclough, Ruth Wodak y Teun van Dijk. Sin embargo, el apelativo de análisis crítico del discurso cambia a partir de la observación que hace van Dijk en la segunda edición del manual de Wodak \& Meyer, Methods of Critical Discourse Analysis (2009). En esta edición el autor holandés sostiene que el ACD no se limita al análisis aplicado, sino que también incluye desarrollos filosóficos, teóricos, metodológicos y prácticos. Por lo tanto, y para no caer en el error de considerar el ACD un método, era preferible usar el término de ECD:

Although critical approaches to discourse are commonly known as Critical Discourse
Analysis (CDA), I prefer to speak of Critical Discourse Studies (CDS). This more general
term suggest that such a critical approach not only involves critical analysis, but also cri-
tical theory, as well as critical applications. The designation of CDS may also avoid the
widespread misconception that a critical approach is a method of discourse analysis.

(van Dijk 2009, p. 62)

Esta observación ha sido tan aceptada que la tercera edición del influyente manual de Wodak y Meyer (2016), se publica con el título de Methods of Critical Discourse Studies. Basándose en este antecedente, los editores del The Routledge Handbook 
of Crical Discourse Studies (2018), John Flowerdew y John E. Richardson, declaran haber decidido modificar el título del volumen actualizándolo con el rótulo de ECD (2018, p. 2). Aun cuando actualmente se sigue hablando de análisis crítico del discurso y no todos los estudiosos que enmarcan sus investigaciones dentro de la perspectiva crítica han optado por actualizar el nombre, nosotros nos alineamos con los motivos expuestos por van Dijk y usamos el término de ECD para referirnos al enfoque desde el que tratamos esta investigación.

\subsection{Los enfoques más conocidos, principios y temas en común}

De acuerdo con Hart (2010, p. 14), los enfoques mejor establecidos y con mayor tradición dentro de los ECD son cuatro: la lingüística crítica (Fowler et al. 1979; Fowler 1991; Kress 1985; Kress \& Hodge 1979); el enfoque sociosemiótico (Fairclough 1989, 1992, 1995); el enfoque histórico-discursivo (Reisigl \& Wodak 2001; Wodak 1996, 2001), y el enfoque sociocognitivo (van Dijk 1995, 1998, 2002). Cada uno de estos enfoques se distingue de los demás por las teorías y las herramientas metodológicas que aplica para su análisis - siendo la lingüística sistémico-funcional (Halliday 1973) una de las teorías más recurrentes-. Sin embargo, comparten una misma perspectiva (crítica) y ciertos principios. Fairclough \& Wodak (1997, pp. 271-280) apuntan ocho principios centrales de los ECD:

(1) Los ECD se ocupan de problemas sociales.

(2) Las relaciones de poder son discursivas.

(3) El discurso constituye la sociedad y la cultura.

(4) A través del discurso se realiza un trabajo ideológico.

(5) El discurso es histórico.

(6) El vínculo entre el texto y la sociedad es mediado.

(7) Los ECD son explicativos e interpretativos.

(8) El discurso es una forma de acción social.

Como se puede observar de los principios arriba citados, algunos de los temas recurrentes y directamente vinculados con los objetivos de estudio de los ECD son el discurso, la ideología, el poder, y como profundizaremos más adelante, la identidad.

No hay una definición única y consensual de discurso y muchas veces esta noción resulta difusa y ambigua (van Dijk 2008, p. 21). Por ejemplo, se puede hablar de discurso -en singular- como un suceso de comunicación o, más concretamente, para referirse a una producción lingüística determinada. Pero también se usa el término discurso o discursos - en plural- para aludir a prácticas discursivas conformadas por ideas o ideologías grupales (van Dijk 2008, p. 25), 
por ejemplo, el discurso feminista, neoliberal, etc. Es en este último sentido que los ECD tratan la noción de discurso -y como será entendida en esta investigación-. Además, los ECD consideran que el discurso (o los discursos) no se expresa(n) únicamente a través de la producción lingüística, sino también mediante diferentes sistemas semióticos incluso multimodales (cfr. Machin \& Mayr 2012, 2018; Kress \& van Leeuwen 1996).

Los discursos están fundamentados en ideologías. De acuerdo con van Dijk (1998) las ideologías son sistemas de creencias y valores adquiridos, compartidos, usados y modificados por los miembros de un grupo (1998, p. 126). Son representaciones mentales compartidas que se (re)producen en las prácticas sociales, a través del discurso y de los discursos. Por esta razón, van Dijk (1998; 2002) afirma que la ideología tiene una dimensión social y una cognitiva.

Las ideologías representan "axiomas” de creencias sociales (van Dijk 1998, p. 128), es decir, se trata de creencias incuestionables y relativamente estables consideradas naturales y lógicas por un colectivo. Estas ideas no son personales ni provienen de la experiencia directa del individuo con su medio, sino que son diseminadas por una o varias "autoridades" y son aprendidas y aceptadas por los individuos que han legitimado esa(s) "autoridad(es)". Las ideologías se concretizan y manifiestan a través de determinadas proposiciones que proponemos llamar ideologemas.

El término ideologema fue introducido por Marc Angenot (1982, pp. 179-182) para referirse a lugares comunes o máximas que funcionan como presupuestos del discurso. Narvaja de Arnoux \& del Valle (2010) retoman dicho término en sus investigaciones sobre ideologías lingüísticas. Los autores consideran los ideologemas como condensados ideológicos, máximas o principios que dominan en un campo discursivo, una época o una institución y explican que "la imposición de un nuevo ideologema se logra cuando naturaliza lo que enuncia generalizando su aceptación hasta el punto de bloquear la posibilidad de su lectura crítica o problematización" (2010, p. 13). En este sentido, estas proposiciones son generalizadoras y son utilizadas de manera rutinaria, natural e incuestionable por los miembros de los grupos que asumen cierta ideología. Así, por ejemplo, ideologemas del discurso xenófobo serían "los inmigrantes son delincuentes", "le roban el trabajo a la población”, "son una carga para la sociedad”, "ponen en riesgo la estabilidad económica y social del país”.

Otro concepto sobre el cual los ECD vuelcan su atención es el de poder. Michel Foucault ha sido uno de los estudiosos que han teorizado sobre este concepto y ha sido referencia para los ECD. Foucault $(1972,1979)$ se ha concentrado en diferentes formas de poder, en sus raíces históricas y en las prácticas de dominación asociadas a los diferentes tipos de poder. Para este estudioso, el poder es omnipresente en todas las sociedades y regula su funcionamiento. Sin embargo, 
no considera el poder como mera represión, no es algo aplicado, sino practicado (Nealson 2008, p. 24). Es decir, el poder no es simplemente un sistema de control y represión, el poder crea deseos, establece objetos de conocimiento, legitima discursos y determina lo que puede ser dicho, cómo y por quién. En este sentido, para el autor, el discurso es al mismo tiempo producto y herramienta de los mecanismos de poder. Otros autores que han contribuido a entender el funcionamiento del poder son Antonio Gramsci y Pierre Bourdieu. Gramsci (1930), por ejemplo, mediante su teoría de la hegemonía, sostiene que el poder se ejerce no solo mediante la violencia y la coerción política, sino también ideológicamente, a través de una cultura hegemónica en la que los valores de la burguesía son aceptados y considerados "sentido común":

l'esercizio "normale" dell'egemonia [. . .] è caratterizzato da una combinazione della forza e del consenso che si equilibrano, senza che la forza soverchi di troppo il consenso, anzi appaia appoggiata dal consenso della maggioranza espresso dai così detti organi dell'opinione pubblica (Quaderni del Carcere 1, p. 48).

De esta manera se desarrolla una cultura de consenso en la que las personas de la clase trabajadora identifican su propio bien con el bien de la burguesía y ayudan a mantener el statu quo.

De acuerdo con Bourdieu (1977), para que los grupos o individuos puedan imponer el poder es necesario que alcancen un nivel simbólico, es decir, que logren “naturalizar” y convencionalizar ideas, valores, prácticas y marcos de entendimiento de la realidad. La dominación, pues, es alcanzada mediante la internalización de ciertas creencias y valores, esto es, de ideologías. La adquisición de tales estructuras mentales es esencial para el mantenimiento del poder (1977, p. 176).

\subsection{La identidad: del esencialismo al construccionismo}

Como se ha dicho precedentemente, la identidad es uno de los tópicos más tratados dentro de los ECD. Los primeros esfuerzos por teorizar esta noción datan del s. XVI (Taylor 1989) como producto de preocupaciones filosóficas. A partir de entonces, la noción se ha tratado principalmente desde dos perspectivas diferentes: una visión “esencialista” vs. una visión “constructivista” (Benwell \& Stokoe 2006). Las teorías esencialistas tratan la identidad como un constructo personal, interno, estable y prediscursivo, producto de la cognición humana. En sus inicios, tal concepción se desarrolló a partir de dos corrientes opuestas: de las ideas del racionalismo deductivo de Descartes (1596-1650) caracterizadas por la confianza plena en la capacidad cognoscitiva innata; y en las ideas de 
Locke (1632-1704), según el cual los conocimientos proceden de la experiencia que se adquiere mediante la sensación y la reflexión. Tales posturas dieron origen a una concepción de la identidad como un constructo interno, es decir, como un project of the self (Benwell \& Stokoe 2006). Esta idea dominó desde el Iluminismo, fue heredada por el Romanticismo (donde se consideró el “yo” como una expresión innata basada, no ya en la cognición, sino en la sensibilidad y los sentimientos) y fue retomada por el psicoanálisis freudiano de principios del s. XX.

La concepción de la identidad cambió en la segunda mitad del s. XX, cuando sociólogos y psicólogos sociales se empezaron a interesar por la teorización de las identidades grupales con las que los individuos se identificaban o rechazaban. Es decir, la identidad se comenzó a tratar como un producto social intersubjetivo (Benwell \& Stokoe 2006). En esta línea surge la teoría de la identidad social, desarrollada por el psicólogo social H. Tajfel $(1981 ; 1982)$ y su equipo de colaboradores (Tajfel \& Turner 1986). Tajfel (1981, p. 225) define la identidad social como:

[. . .] that part of the individual's self-concept which derives from his knowledge of his membership in a social group (or groups) together with the value and emotional significance attached to that membership.

Dicho de otro modo, este conocimiento del individuo sobre su pertenencia a un grupo es un reconocimiento, es decir, una aceptación de él mismo como miembro de un colectivo con el que se identifica. De acuerdo con esta teoría, la construcción de la identidad social implica varios procesos psicológicos como la categorización social, la identificación con una categoría social, la comparación y diferenciación entre categorías (Tajfel \& Turner 1986, p. 40).

La identidad social, pues, es considerada por Tajfel \& Turner (1986, p. 40) como "those aspects of an individual's self-image that derive from the social categories to which he perceives himself as belonging". Como se puede observar en la cita, aunque esta perspectiva enfatiza el aspecto social de la identidad, sigue considerando el "yo" como un fenómeno interno y prediscursivo.

Las teorías construccionistas surgidas a finales del s. XX, en cambio, consideran que la identidad es un fenómeno dinámico, fragmentario, contingente y construido en el discurso. Se concibe la identidad como un aspecto interno que se desarrolla y exterioriza a partir del discurso y de otros sistemas semióticos (como los gestos, la manera de vestir y de hablar, etc.) (Benwell \& Stokoe 2006, p. 4). Pero, además, la construcción y reconocimiento del "yo" surge en y a partir de la interacción social. Algunas de las aproximaciones discursivas que adoptan una perspectiva construccionista de la identidad son el análisis de narrativas y los estudios críticos del discurso. Como hemos apuntado y profundizaremos más adelante, ambos enfoques combinan el nivel de análisis micro con el macro. Para el 
análisis de narrativas la identidad es construida en las historias que contamos sobre nosotros mismos y lo que nos rodea; además - para los enfoques sociointeraccionales a la narrativa (De Fina 2003)-, esta se construye en colaboración con los interlocutores y es dependiente del contexto. Por lo tanto, la identidad es un fenómeno dinámico.

Para los estudios críticos del discurso, parte de la identidad está modelada por discursos hegemónicos e ideologías con los que los actores sociales se identifican, que rechazan o asumen como verdaderos. En efecto, desde su enfoque sociocognitivo, van Dijk (1998, p. 128) afirma que la identidad grupal está fundamentada en una ideología, es decir, en "axiomas” de creencias sociales. Según esta línea, la identidad (tanto grupal como individual) comprende una dimensión social, porque se construye a partir de la interacción con otros y es elaborada y negociada a través del discurso, pero también posee una dimensión cognitiva porque se cimienta en creencias personales y compartidas (van Dijk 1998).

En esta investigación tratamos la identidad grupal, en específico la identidad nacional desde una óptica construccionista. En este sentido, entendemos la identidad como un fenómeno a) sociocognitivo; b) multidimensional; c) interaccional; d) dinámico; e) discursivo; f) categorizador y comparativo; g) ideológico.

a) La identidad es un constructo cognitivo porque se cimienta en representaciones mentales, creencias personales y compartidas (van Dijk 1998). Sin embargo, esto no significa que el "yo" se construye independientemente dentro de la mente del individuo. El proceso de formación de la(s) identidad(es) se realiza a partir de la formación de modelos mentales (Lakoff 1987) o categorías cognitivas (Lakoff 1987, p. 69; van Dijk 1998) que se desarrollan, se fijan y se asumen como propias únicamente a partir del discurso y de la interacción social. Así, la identidad colectiva se adquiere a partir de la experiencia social y de las ideas que surgen a partir de esta. Dicha experiencia se organiza en un esquema mental de autorrepresentación grupal que permite al individuo definir a su propio grupo o grupos (van Dijk 1998).

b) La identidad es un fenómeno multidimensional, ya que poseemos distintas identidades: nos reconocemos dentro de categorías sociales a nivel macro, y al mismo tiempo nos concebimos como únicos, es decir que poseemos una identidad personal. El despliegue de una u otra identidad dependerá de las demandas del contexto; esto significa que nos concebimos y nos conciben de diferentes maneras según el contexto situacional en el que interactuamos socialmente.

c) La identidad es un fenómeno interaccional porque el despliegue de la(s) identidad(es) emerge (Bucholtz \& Hall 2005) solo a partir de la interacción social (De Fina 2006; van Dijk 1998). 
d) Es un proceso dinámico porque se encuentra en constante desarrollo y reelaboración (De Fina 2006). En la interacción, los hablantes no recrean una única categoría identitaria, sino que pueden ir tomando diferentes posiciones de acuerdo a sus fines comunicativos (Bucholtz \& Hall 2005).

e) De los puntos anteriores se desprende que la identidad es un fenómeno discursivo ya que es a partir del discurso que los hablantes manifiestan sus identidades. En efecto, las posiciones identitarias se construyen y son reconocidas por los interlocutores mediante el mecanismo de indexicalización (cfr. Ochs 1992; Silverstein 1985). Este mecanismo es fundamental para entender cómo algunas formas lingüísticas remiten a significados y categorías sociales, y, por lo tanto, señalan identidades específicas (Bucholtz \& Hall 2005).

f) La identidad implica los procesos de categorización y comparación. Como lo expone la teoría de la identidad social (a partir de aquí TIS; Tajfel \& Turner 1986), la construcción identitaria sigue los principios de inclusión-exclusión e identificación-diferenciación. Procesos que se llevan a cabo a partir de modelos mentales cargados de elementos afectivos y juicios de valor, creados en la interacción y almacenados en la memoria. Según la TIS los individuos tienden a desear una identidad social positiva, lo cual es el motor de las acciones del individuo en contextos intergrupales y es mediante la comparación que el individuo obtiene una evaluación de la posición y el estatus social de su grupo (Taylor \& Moghaddam 1994, p. 79). En esta línea, van Dijk (1998; 2001) afirma que uno de los procesos que comprende la autocategorización grupal es la determinación del "otro” en oposición al "nosotros". En efecto, los individuos crean representaciones positivas de su ingroup y negativas del outgroup. La estrategia discursiva con la cual se construye la autorrepresentación grupal consiste en a) enfatizar/hablar de nuestros aspectos positivos; b) enfatizar/hablar de sus aspectos negativos; c) quitar énfasis/no hablar de nuestros aspectos negativos; d) quitar énfasis/no hablar de sus aspectos positivos (van Dijk 1998, p. 44; 2001, pp. 57-58).

g) Finalmente, la identidad -especialmente la grupal- es un fenómeno ideológico, ya que descansa en ideologías, es decir, en sistemas de creencias compartidas, más o menos estables y naturalizadas, sobre lo que significa(n) nuestro(s) grupo(s) en comparación con otros grupos, así como ideas sobre nuestra posición en la sociedad (van Dijk 1998, p. 121). Además, como afirman Bucholtz y Hall (2005, p. 594), la asignación de individuos en categorías sociales a partir de rasgos lingüísticos (indexicalización) reside en creencias y valores culturales, es decir, en ideologías: 
In identity formation, indexicality relies heavily on ideological structures, for associations between language and identity are rooted in cultural beliefs and values - that is, ideologies - about the sorts of speakers who (can or should) produce particular sorts of language.

Al ser ideológica, la construcción de la identidad puede ser un acto de poder, ya que los grupos hegemónicos pueden construir con bastante libertad su propia identidad y al mismo tiempo imponer o negar identidades a grupos marginales. En esta línea Bauman (2005, pp. 86-87) afirma que:

[. . .] en un extremo de la jerarquía global emergente están los que pueden componer y descomponer sus identidades más o menos a su voluntad tirando del fondo de ofertas extraordinariamente grandes de alcance planetario. El otro extremo está abarrotado por aquellos a los que se les ha vedado el acceso a la elección de identidad, gente a la que no se da ni voz ni voto para decidir sus preferencias y que, al final, cargan con el lastre de identidades que otros les imponen y obligan a acatar.

En efecto, las instituciones hegemónicas, dentro de las cuales está el sistema educativo, tienen el poder de difundir ideologías y con ello modelar identidades o incluso negarlas, tal es el caso de la figura del indígena en los LTG, a la que daremos luz en los siguientes capítulos.

\subsection{El papel de la cognición dentro de los ECD: el enfoque sociocognitivo}

Como indicamos anteriormente, uno de los principios fundamentales de los ECD apunta que el vínculo entre el texto y la sociedad es mediado. De acuerdo con van Dijk, este vínculo es la cognición.

A lo largo de su amplia investigación sobre el discurso y la ideología, van Dijk (1985, 1993, 1998, 2008, 2009) desarrolló un enfoque al que denominó sociocognitivo en el cual las estructuras sociales, cognitivas y textuales están estrechamente relacionadas. En su propuesta, las nociones de cognición y sociedad se entienden en un sentido amplio, englobando dentro de la primera las representaciones sociales e individuales de la memoria, los procesos mentales, el pensamiento y la emoción. Por su parte, la sociedad es entendida "tanto en el micronivel, el de las situaciones y las interacciones sociales como en el macronivel de los grupos, de las relaciones grupales, de las instituciones, de los sistemas abstractos y del orden social en general" (1997, p. 67). Para van Dijk, la interfaz que media entre las estructuras textuales y las sociales es la cognición social, que define como "the system of mental representations and proceses of group members" (van Dijk 1995, p. 18). La cognición social está formada por estructuras y representaciones sociales 
almacenadas en la memoria de los individuos que se manifiestan y se transmiten como actitudes, ideologías, opiniones y prejuicios a través de la producción textual. Para explicar la relación entre el discurso, la sociedad y la cognición social, el autor recurre a la imagen de un triángulo donde cada ápice representa una de estas nociones. La interrelación entre los tres ápices se deriva de la dependencia y la influencia que hay entre ellos, esto es, el discurso está condicionado por las estructuras sociales y construido por la acción cognitiva, pero al mismo tiempo condiciona la interacción y la acción social, así como la construcción de nuevas representaciones mentales. Por su parte, los procesos mentales no solo condicionan el discurso, sino también la interacción y la organización social.

Dentro de este enfoque, la memoria, el conocimiento y la manera en que este se almacena tienen un papel muy importante. Van Dijk diferencia dos módulos básicos de la memoria: memoria a corto plazo (short-term memory) y memoria a largo plazo (long-term memory); esta última subdividida a su vez en otros dos submódulos: memoria semántica o social (semantic memory), en la cual se almacenan los esquemas mentales compartidos (representaciones sociales), y memoria episódica (episodic memory), donde se acumulan las experiencias autobiográficas personales (2003, p. 21).

La producción y comprensión de un discurso dependen de un gran conjunto de conocimientos que deben estar organizados de tal manera que sean accesibles rápidamente y que permitan al usuario del lenguaje recuperar información faltante, reconocer el tema, predecir el sentido del discurso y los objetivos del hablante. En esta línea, mostrando mucha similitud con las teorías cognitivas de los marcos (frames) (Fillmore 1985; 2006) o los modelos cognitivos idealizados (Lakoff 1989), van Dijk formula la hipótesis de que "el conocimiento forma una red compleja de nudos que representan conceptos que son multiplicados, relacionados con otros nudos/conceptos, o representan conocimiento en términos de esquemas o guiones con algunas categorías fijas y nudos terminales variables” (2002a, p. 8). Así, propone que existen tres tipos de modelos mentales: modelos de situación, modelos generales y modelos de contexto. Los primeros son llamados "de situación" debido a que cuando los oyentes reciben una información, por ejemplo, leen un texto o escuchan una historia, tratan de "imaginar" aquello a lo que el texto se refiere, es decir, construyen el evento en la mente: los participantes, los actos, el escenario (tiempo y lugar) reportado a través del discurso (van Dijk 1993, p. 41; 2003, p. 21; 2012, p. 108). Estos modelos son construidos sobre la base de conocimientos personales (adquiridos de manera directa - vivencialo indirecta - transmitida-) y conocimientos socialmente compartidos. Cuando el oyente recibe información, recupera el formato que más se ajusta a la información recibida y sobre la base de ese esquema adapta las propiedades que percibe de la situación ofrecida por el discurso que está recibiendo (van Dijk 1993, p. 42). 
Los modelos generales son formatos esquemáticos de conocimientos compartidos (como por ejemplo, las representaciones que se hacen de los objetos, de personas, grupos o estructuras sociales) y episodios comunes (como hacer las compras, ir al cine, cenar en un restaurante, asistir a una conferencia, etc.). Estas representaciones están conformadas por conocimiento general organizado en términos de marcos, formatos o guiones (scripts) (Schank \& Abelson 1977; 1987). ${ }^{1}$

En el proceso discursivo, tanto en la producción como en la comprensión, los usuarios de la lengua hacen una representación mental de los eventos sobre los que habla o escucha (modelos de situación), pero también construyen modelos mentales de los eventos en los que participan (2002a, p. 9). A este último tipo de representaciones mentales, van Dijk las llama modelos de contexto (1993, p. 46; 2002b, p. 61; 2012, p. 39). Estos modelos se construyen a partir del conocimiento personal y social y consisten en un esquema de categorías que definen el evento comunicativo. De acuerdo con van Dijk (2012, pp. 122-123), estas categorías son el escenario (tiempo/periodo, espacio/lugar/ambiente), los participantes y las acciones.

Los modelos contextuales tienen un rol primordial en la producción e interpretación del discurso, ya que representan el modo en que los hablantes/oyentes simbolizan y evalúan la situación comunicativa y de acuerdo a ello adecúan su discurso. Esto significa que, cuando los modelos contextuales se han construido parcialmente, puesto que los modelos se pueden modificar a lo largo del discurso- los hablantes pueden decidir sobre el tipo de conocimiento personal o social que podrán expresar, la información que debe ser señalada y la que puede dejarse implícita (2002a, p. 10, 2012, p. 107). Por lo anterior, van Dijk sostiene que los modelos contextuales controlan el evento comunicativo (2002a, p. 10).

\subsection{De la fase descriptiva a la fase interpretativa}

Con excepción del enfoque sociocognitivo de van Dijk, los ECD habían mostrado renuencia por aceptar las aproximaciones cognitivas para tratar fenómenos sociales manifestados mediante la lengua. La inquietud por la carencia de estudios de corte cognitivo se mostraba todavía a principios del s. XXI (cfr. Koller 2005).

1 Shank y Abelson definen la noción de guión mental de la siguiente manera: "un guión es una secuencia de acciones predeterminada y estereotipada que define una situación bien conocida" (1987: 56) 
De acuerdo con Hart (2010, p. 19), el tipo de análisis que había prevalecido dentro de los ECD había sido el descriptivo, basado en la lingüística sistémico-funcional de Halliday, mientras que los niveles de interpretación y explicación ( $c f r$. Fairclough 1995, p. 97) habían sido poco explorados. Sin embargo, poco a poco los analistas del discurso han ido coincidiendo en la necesidad de entender mejor los procesos cognitivos implicados en la producción y recepción textuales, pues son estos los que realmente posibilitan la interiorización de determinadas categorías de pensamiento, muchas de las cuales forman parte de las ideologías. De tal suerte, se han ido desarrollado nuevas direcciones de análisis crítico dentro de la rama cognitiva sobre todo basadas en las propuestas teóricas de la lingüística cognitiva (LC) (cfr. Dirven, Frank \& Putz 2003, Dirven, Polzenhagen \& Wolf 2007) y la psicología evolutiva (Chilton 2004; Hart 2010, Hart 2011).

El modelo de cognición social desarrollado por van Dijk postula que para entender las creencias, actitudes e ideologías que dan pie a las injusticias sociales y que se transmiten a través de los textos es necesario atender cómo perciben los hablantes el mundo social, de qué manera se crean las representaciones mentales de dicho mundo y qué procesos se ponen en funcionamiento tanto para producirlas en el discurso como para comprenderlas (van Dijk 2009, p. 64). Por esta razón, la única manera de entender la relación entre las estructuras sociales y el lenguaje es a través de una teoría cognitiva. Aunque el modelo de van Dijk se ve ampliamente respaldado por otros similares propuestos en la psicología social (cfr. Moskovici 1984; Farr \& Moskovici 1984; Fiske \& Taylor 1991), como señala Hart (2010, p. 23) "[van Dijks] socio-cognitive approach does not describe the precise forms of these social cognitions or exactly how they may be derived from linguistic representations in text”. Por lo anterior, recientemente varios analistas críticos (cfr. Dirven, Frank \& Putz 2003; Dirven, Polzenhagen \& Wolf 2007; Koller 2005, 2014; Hart 2010) han encontrado en la lingüística cognitiva un marco teórico que se alinea con los objetivos de investigación de los ECD.

La LC ofrece un marco teórico y sobre todo herramientas conceptuales para el análisis que pueden alinearse y complementar el modelo sociocognitivo propuesto por van Dijk, ya que permite explicar la manera en que se manifiestan determinadas estructuras lingüísticas y el proceso cognitivo mediante el cual les asignamos significado.

Aunque poco explorada, la combinación del enfoque crítico con el cognitivo ya aparecía en las ideas tanto de analistas críticos como de lingüistas cognitivos desde hace varias décadas. Por ejemplo, en 1979, en una obra seminal para el desarrollo posterior del ACD, Hodge y Kress, exponían claramente la interrelación entre lenguaje y cognición: 
We regard language as consisting of a related set of categories and processes. [. . .] [C]ategories are regarded as a set of 'models' which describe the interrelation of objects and events. These models are basic schemata which derive in their turn from the visual perceptual processes of human beings”. (Hodge \& Kress 1979, p. 7).

Kress en Linguistics processes in sociocultural practice (1989) demuestra ser consciente de que la metáfora es omnipresente y esencial tanto en las actividades lingüísticas como cognitivas. Es justamente la teoría de la metáfora conceptual (TMC, Lakoff \& Johnson 1980) la herramienta cognitiva que ha sido más explorada dentro de los ECD. El análisis crítico de la métáfora (Charteris-Black 2004) ha sido el modelo que demuestra abiertamente la aplicación de la LC a la investigación sobre ideología. Este paradigma se basa en la TMC para investigar el rol ideológico de la metáfora en la construcción de la realidad social y la asimilación de ciertos modelos mentales que están al servicio de los intereses de grupos dominantes.

Aunque la metáfora ha sido una operación muy fructífera para develar la ideología desde una perspectiva crítica y cognitiva, no es la única operación que puede contribuir al análisis de discursos ideológicos (Koller 2014). Como afirman Dirven et al. (2003, p. 4) “[. . . ] cognitive linguistics has much more to contribute to the study of ideology tan its know-how on metaphor and metaphorical thought”. Y es lo que intentaremos demostrar con esta investigación.

\subsection{La multimodalidad dentro de los ECD}

Para los ECD la lengua es solo una de las maneras que utilizamos en la construcción del sentido, ya que además de esta existen otros modos que aprendemos a percibir y a utilizar como estrategias de significación. Es decir, los ECD reconocen la naturaleza semiótica y multimodal de la comunicación. La multimodalidad dentro de los ECD ha sido uno de los aspectos que se han tomado en cuenta para develar la carga ideológica y las relaciones de poder que implican ciertos elementos visuales y auditivos en combinación con la lengua. Este ámbito se encuentra todavía en desarrollo, lo cual se observa en la no muy extensa bibliografía existente dentro de los ECD (Ledin \& Machin 2018, p. 60). Una de las obras fundadoras en el campo de la multimodalidad fue Reading Images (1996) escrita por Gunther Kress y Theo van Leeuwen. Basándose en conceptos de la lingüística sistémico-funcional (Halliday 1978), la psicología visual y la semiótica social, los autores se propusieron identificar las regularidades de la comunicación a través de la imagen y las relaciones sociales e ideológicas que conlleva la elección y disposición de los elementos dentro del espacio visual. El marco teórico que desarrollan en esta obra pionera nos resulta ideal para el análisis de los libros de texto, ya que al ser destinados a niños contienen gran 
cantidad de elementos visuales que juegan un papel fundamental en la construcción de significados sociales.

\subsubsection{La semiótica social}

El término de semiótica social fue introducido en la lingüística por Halliday en su libro Language as social semiotic (1978). Desde la línea de la lingüística crítica, Bob Hodge y Gunther Kress (1988) desarrollaron el término basándose en las ideas hallideanas y aplicándolas al análisis de otros modos de representación. Así, la semiótica social se vuelve un marco teórico que investiga la producción de significado en circunstancias sociales y culturales específicas, es decir, entiende el significado como una práctica social. La semiótica social considera que los significados y los sistemas semióticos están moldeados por procesos sociales y relaciones de poder, y a medida que el poder cambia en la sociedad, la lengua y otros sistemas de significados también cambian. La semiótica social comprende, por lo tanto, el estudio de las dimensiones sociales del significado, así como las relaciones de poder de los procesos de significación e interpretación y de cómo estos procesos afectan en la configuración de individuos y sociedades (Hodge \& Kress, 1988).

La semiótica social se ha centrado en las prácticas de creación de significado social de todo tipo, es decir, se ha interesado por analizar los diferentes modos semióticos (recursos visuales, verbales, escritos, gestuales y musicales) y la combinación de varios de ellos. Teóricos como Kress y van Leeuwen (1996) se han avocado al estudio de la comunicación multimodal y han aportado un marco teórico para el análisis crítico de las representaciones visuales.

\subsubsection{Una gramática de las representaciones visuales}

A partir de la idea de que las representaciones visuales pueden leerse como un texto y que están constituidas por elementos que se combinan siguiendo ciertas normas para construir significados socialmente compartidos, Kress y van Leeuwen (1996) acuñan la noción de "gramática del diseño visual”. En palabras de los autores:

Just as grammars of language describe how words combine in clauses, sentences and texts, so our visual 'grammar' will describe de way in which depicted elements - people, places and things- combine in visual 'statements' of greater or lesser complexity and extension. (2006, p. 1) 
El estudio de Kress y van Leeuwen busca ofrecer descripciones útiles de las principales estructuras composicionales que se han vuelto convencionales a lo largo de la historia de la semiótica social occidental y develar la manera en que estas estructuras han sido usadas para producir significado.

Aun cuando los autores no adoptan explícitamente una postura cognitivista, coinciden perfectamente con la visión langackeriana que sostiene que la lengua cuenta con diversos medios para representar una misma situación (Langacker llama a esta capacidad imagery -1987, p. 110- o construal -2008, p. 43-). Esta misma idea es aplicada a las representaciones visuales. Esto es, Kress y van Leeuwen (1996) sostienen que, así como la elección de palabras o de ciertas estructuras lingüísticas revela determinadas interpretaciones de la experiencia y de la interpretación del mundo de los hablantes, asimismo las imágenes expresan la manera en que el productor de imágenes conceptualiza el entorno y guían al observador hacia ciertas interpretaciones. En este sentido dicen que:

What is expressed in language through the choice between different word classes and clause structures, may, in visual communication, be expressed through the choice between different uses of color or different compositional structures. And this will affect meaning. Expressing something verbally or visually makes a difference. (2006, p. 2)

Es por lo anterior que los autores consideran que la elección de los signos que constituyen una imagen no es arbitraria, sino que todos los productores de signos (adultos o niños) por naturaleza focalizan y representan los elementos que para ellos son esenciales del objeto que quieren expresar visualmente. Estos elementos dependen de -o están mediados por- aspectos culturales, sociales y/o psicológicos de la historia del productor de signos, así como del contexto en el que se realiza el signo (2006, pp. 7-8).

?A3B2 tlsb -0.01w?>Para hablar de los elementos que componen la estructura o la gramática de la imagen y de las relaciones que se establecen entre estos elementos, los autores utilizan algunos términos de la lingüística funcional tales como los de participantes activos y participantes representados, actor, meta, relación transaccional, etc.

Así, los elementos que constituyen el producto visual pueden ser internos, es decir, las personas, lugares y cosas ilustrados en la imagen, o externos, o sea, las personas que se comunican a través de la imagen (los productores y los observadores). Kress y van Leeuwen (2006, p. 114) llaman a los elementos internos participantes representados (represented participants) y a los externos participantes activos (active participants). Los participantes representados cumplen diferentes roles dentro de la imagen. Se les llama actores (Actor) a los participantes que realizan la acción y metas (Goal) a los que reciben la acción. La relación que se puede crear entre estos dos participantes es de tipo transaccional y 
se realiza a través de vectores (vectors). Es decir, una imagen desencadena un proceso narrativo en el que hay participantes que están "haciendo algo" (una acción en desarrollo) y sus acciones recaen sobre sí mismos o sobre otros participantes. Esta conexión entre los participantes ocurre a través de vectores. Tales vectores se observan mediante elementos de la imagen que forman una línea oblicua, normalmente en forma de una línea diagonal. Estas líneas pueden estar formadas, por ejemplo, por los cuerpos de los participantes, por sus extremidades o por instrumentos que estos sostienen (2006, p. 59). El actor es el participante del cual parte el vector y puede estar fusionado con este. Es normalmente el participante más destacado. La meta, en cambio, es el participante hacia el cual apunta el vector y para el cual están dirigidas las acciones del actor. Cuando la imagen contiene un solo participante, este es regularmente un actor. Una estructura como esta en la que no hay meta es denominada proceso no transaccional (non-transactional, 2006, p. 63) y se puede paragonar con el proceso narrativo compuesto por verbos intransitivos (mientras que el transaccional sería equivalente al proceso en el que se usan lingüísticamente verbos transitivos).

Las estructuras transaccionales y no transaccionales no son los únicos tipos de estructuras que se pueden realizar visualmente. Existe también un tipo de estructura o proceso al que llaman analítico (2006, p. 50) donde los participantes no tienen los roles de actor y meta, sino los de portador (Carrier) y atributo (Attribute). Las imágenes que ostentan este proceso no muestran a los participantes "haciendo algo" o dirigiéndose a otros participantes, sino que los muestran unidos formando un conjunto más grande. El participante más grande que representa el todo en su conjunto es el portador, mientras que los participantes o partes que lo componen son los atributos posesivos (Possessive Attributes).

Otros procesos destacados por los autores (2006, p. 67) son los procesos de reacción (reactional processes) que se suscitan cuando el vector es la línea que se forma a partir de la mirada de uno o más participantes representados. El participante, cuya mirada crea una línea (vector) que enfoca a otro participante, es el reactor. Este, debe ser necesariamente un humano o un animal u objeto humanizado que posea ojos visibles al observador y una expresión facial. El participante o participantes a los que el reactor dirige la mirada es/son el fenómeno (Phenomenon). Este puede ser un participante o una entera proposición visual. $\mathrm{Al}$ igual que los procesos de acción, también los procesos de reacción pueden ser transaccionales o no transaccionales. Este último caso ocurre cuando visualmente no está presente el fenómeno al que el reactor está mirando.

Existen también participantes secundarios dentro de la imagen cuya presencia o ausencia no afecta a la proposición básica del proceso narrativo pero cuya elisión, sin embargo, implicaría la pérdida de cierta información. A esto participantes se les llama circunstancias (Circumstances, 2006, p. 72). El escenario 
donde se ubica la imagen forma parte de las circunstancias locativas y se le conoce como setting. El setting implica un contraste entre el primer y el segundo plano (foreground y background). Es opacado por los participantes cuando se encuentran en primer plano y regularmente es representado en menor detalle.

Finalmente, hay imágenes en las que no hay vector alguno que relacione a los participantes. La relación que se muestra en imágenes de este tipo se conoce como circunstancia de acompañamiento (Circumstance of Accompaniment), la cual se interpreta como un proceso analítico, ya que la información que ofrece es descriptiva y no presenta una narrativa de acciones.

\subsubsection{La composición visual y sus significados}

La imagen es un espacio (visual) que comunica significados a través de las relaciones que se establecen entre los elementos que la constituyen. Los observadores reconstruyen el significado del espacio visual a partir de las relaciones espaciales entre los participantes representados y las relaciones sociales que se establecen entre ellos. Es a partir de estas relaciones que se pueden develar las ideologías subyacentes.

Desde un punto de vista de los ECD, el uso de las relaciones espaciales sirve como medio de codificación ideológica para intensificar la capacidad persuasiva del producto visual (Dezheng 2011, p. 57). De acuerdo con Kress y van Leeuwen (2006, p. 177), la relación espacial implica simultáneamente tres sistemas significativos: la saliencia o prominencia (salience), el enmarcado (framing) y el valor que se le da a la información (information value).

La saliencia es el grado de importancia o fuerza que un elemento adquiere en el espacio visual. Mientras más saliente sea un elemento, captará con más facilidad la atención del espectador. Hay distintos mecanismos a través de los cuales se le otorga relevancia a un elemento. Por ejemplo, el tamaño, la nitidez del enfoque, el contraste, el color, la profundidad (foreground) y el segundo plano (background). Además de estos aspectos visuales, algunos aspectos culturales como la figura humana o ciertos símbolos determinan el nivel de saliencia o jerarquía de importancia entre los elementos de la imagen (Kress \& van Leeuwen 2006, p. 202).

Otro aspecto de la composición de la imagen que expresa determinados significados es el enmarcado, esto es, la presencia de líneas que rodean ciertos elementos dentro del espacio visual. Tales líneas permiten conectar o desconectar elementos dentro de la imagen creando un sentido de pertenencia o distanciamiento. En otras palabras, los componentes de una imagen pueden estar fuerte o levemente enmarcados y cuando el enmarcado es fuerte el elemento es perci- 
bido como una unidad separada del resto de la información (2006, p. 203). Si, por el contrario, no hay líneas o colores que demarquen uno o varios elementos, entonces se crea una sensación de composición conectada donde todos los elementos son una unidad de información. La ausencia de enmarcado pues, fortalece la identidad grupal, mientras que su presencia significa individualidad y diferenciación (2006, p. 203).

Todas estas dimensiones del espacio visual codifican significados abstractos como la importancia, el poder o las emociones. Los elementos de la imagen llamarán la atención del observador, adquirirán y transmitirán estos y otros significados de acuerdo al sitio en el que estén colocados. En este sentido, el valor de la información se crea mediante las relaciones espaciales arriba/abajo (eje vertical), izquierda/derecha (eje horizontal) y centro/margen. Respecto del eje vertical, van Leeuwen y Kress (2006, p. 186) sostienen que cuando un elemento está colocado en la parte superior de la imagen es presentado como ideal y si, por el contrario, aparece en la parte inferior, entonces indica lo real. En cuanto al eje horizontal, la parte izquierda representa lo conocido (Given), lo aceptado, lo familiar, mientras que la parte derecha lo nuevo, lo desconocido, lo problemático y refutable (2006, pp. 181-185). Por lo que respecta a la parte central, el elemento colocado al centro de la imagen es presentado como el núcleo de la información, el elemento principal; el mediador y todos los demás elementos están subordinados a este (2006, p. 196). Sin embargo, Kress y van Leeuwen no explican de dónde provienen estos valores. De ahí que la lingüística cognitiva pueda contribuir a complementar los estudios críticos, ya que, como explicaremos en el siguiente capítulo, da respuesta a esta y otras interrogantes: estos valores tienen su origen en nuestra experiencia corpórea. Como se verá más adelante, Lakoff y Johnson (1980) sostienen que creamos conceptos (conceptualizamos, creamos imágenes mentales) en términos de espacio de acuerdo a la manera como experimentamos el mundo. Es decir, entendemos muchos conceptos mediante metáforas espaciales $u$ orientacionales. Por ejemplo, según la experiencia, algo que está en alto es difícil de alcanzar y por ello se crea la metáfora ARRIBA $\rightarrow$ INALCANZABLE, DIFÍCIL en contraste con ABAJO $\rightarrow$ ALCANZABLE, FÁCIL. Pero además nuestra experiencia cultural clasifica lo que es difícil de poseer como irreal y lo que es difícil de entender como abstracto. Así, la relación espacial arriba se relaciona con lo ideal y esto a su vez se asocia con lo deseable. Según Lakoff y Johnson (1980, p. 51) la metáfora LO BUENO ESTÁ ARRIBA genera la metáfora LO DESEABLE ESTÁ ARRIBA debido a que los conceptos de emociones y estados físicos positivos se ubican arriba. Todo lo contrario expresa la orientación abajo. 


\subsubsection{Interacciones y relaciones conceptuales entre los participantes representados y el observador}

Las relaciones entre el observador y la imagen se establecen poniendo al observador en la posición de lectura que desea el productor en términos de involucramiento/desapego (Kress \& van Leeuwen 2006). Estas relaciones se establecen a través de varios recursos: la mirada de los participantes representados, su postura, la angulación desde donde se observa la escena, la perspectiva y el tamaño del encuadre.

\section{A. El contacto visual y la angulación de los participantes}

Los participantes representados dentro de un espacio visual (sean humanos, animales $\mathrm{u}$ objetos humanizados) pueden establecer una relación con el observador a través de la mirada y de gestos corporales. Kress y van Leeuwen (2006, pp. 118-123) afirman que cuando la figura mira directamente al observador se forma un vector que los une, estableciéndose así una relación social imaginaria. En este tipo de imágenes la figura representada toma la posición de sujeto mientras que el observador la de objeto. Estas representaciones son llamadas demandas (demand) ya que "the participant's gaze (and the gesture, if present) demands something from the viewer, demands that the viewer enter in some kind of imaginary relation with him or her" (2006, p. 118). El tipo de relación que la mirada de estas figuras exige depende de la expresión facial y de los gestos que la acompañan. Por ejemplo, mediante la sonrisa se invita al observador a entrar en una relación amistosa de afinidad con la figura; una mirada fría desdeñosa implica una relación de distancia como la de un superior a un inferior; una expresión seductora invita al observador a sentir deseo por la figura, etc. (2006, p. 118).

Cuando el participante representado no mira hacia el observador entonces no se crea esta relación, el observador es el sujeto y la figura es solo el objeto. En este caso, la figura es un ofrecimiento (offer), ya que "it 'offers' the represented participants to the viewer items of information, objects of contemplation, impersonally, as though they were specimens in a display case” (2006, p. 119).

Así como la mirada de los participantes representados sugiere diferentes relaciones sociales con el observador, los distintos ángulos del cuerpo de las figuras también lo hacen. La angulación supone el punto de vista que el productor de la imagen tiene y busca que adopte el observador. Esta comprende la frontalidad, la oblicuidad, el perfil y el ángulo posterior (back view). La frontalidad representa el máximo involucramiento entre el observador y la imagen. Es decir, los ángulos frontales dicen "What you see here is part of our world, something we 
are involved with” (2006, p. 136). El ángulo oblicuo implica varios grados de interacción intermedia pero en general, el mensaje que comunica el productor visual es "What you see here is not part of our world; it is their world, something we are involved with” (cursivas en el original 2006, p. 136). La representación de perfil, por su parte, expresa un fuerte desapego entre el observador y la imagen, mientras que la vista posterior de la figura supone el máximo desapego y comunica la vulnerabilidad de las figuras.

Kress y van Leeuwen (2006, p. 116) coinciden con los postulados de la LC cuando sostienen que el tipo de relaciones sociales que evocan las imágenes se fundamenta en la experiencia que se tiene de las interacciones sociales cara a cara. En esta línea, se podría decir que la mirada directa de la figura o la ausencia de esta, así como la postura de los participantes representados evocan ciertas metáforas instauradas en la mente y originadas en la experiencia. Esto es, la mirada directa evoca las metáforas $\rightarrow$ INVOLUCRAMIENTO, IDENTIFICACIÓN, DEMANDA DE ATENCIÓN; la ausencia de contacto visual $\rightarrow$ DISTANCIAMIENTO, IMPERSONALIDAD. Por su parte, la postura de los participantes evoca las siguientes metáforas: FRONTALIDAD $\rightarrow$ INVOLUCRAMIENTO; OBLICUIDAD $\rightarrow$ DESAPEGO en distintos grados; PERFIL $\rightarrow$ DESAPEGO; VISTA POSTERIOR $\rightarrow$ MÁXIMO DISTANCIAMIENTO, VULNERABILIDAD. Y, como se mencionó arriba, todas ellas tienen una base experiencial ya que en la comunicación de la vida cotidiana encaramos a la persona con la que queremos interactuar y, sobre todo, lo/la miramos; por el contrario, si no queremos interactuar o tener contacto, volteamos la cara y la mirada.

\section{B. El tamaño del encuadre como distancia social}

La distancia desde la que se toma la fotografía o se presenta la imagen sugiere también diferentes relaciones entre los participantes representados y el observador. Kress y van Leeuwen (2006, p. 124) clasifican esta distancia en primer plano (close shot), plano medio (medium shot) y plano largo (ing. long shot). La asociación DISTANCIA DE LA TOMA $\rightarrow$ DISTANCIA SOCIAL deriva de nuestra experiencia de las relaciones interpersonales y depende de la interpretación que se le da en cada cultura. En la cultura occidental, una distancia muy corta entre los interlocutores implica una relación de intimidad y mientras más distancia hay entre los interlocutores, menos involucramiento emotivo y social. Visualmente, el primer plano, en el que se toman los hombros y el rostro de la figura, y el primerísimo primer plano (close up) que capta solo el rostro desde la base del mentón, crean una distancia personal corta (close personal distance). Los planos medios establecen una distancia personal larga (far personal distance): figuras encuadradas a partir del pecho (plano medio corto, medium close up), de la cintura hacia arriba (plano medio), a partir de mitad del fémur (plano americano, 
cowboyshot) o de las rodillas hacia arriba (medium full shot). El plano entero (full shot), donde el cuerpo completo de la figura abarca todo el encuadre, sugiere una distancia social corta (close social distance). El plano general que presenta a la figura de cuerpo entero, pero además muestra gran parte del fondo, evoca una distancia social larga (far social distance). Finalmente, el plano largo o gran plano general (long shot) que contiene varias figuras de cuerpo entero dentro de un gran escenario que hace que no sean nítidamente reconocibles, crea una distancia pública (public distance) (Kress \& van Leeuwen 2006, pp. 124-125). Asimismo, como sucede en las relaciones interpersonales, las distancias cortas indican relaciones de amistad, confianza, familiaridad, mientras que las largas indican extrañeza u otredad y suponen poco involucramiento emotivo.

\section{La perspectiva 0 angulación de la toma}

Otra dimensión del espacio visual que evoca relaciones sociales es la relación entre el espacio representado y la cámara (en el caso de fotografías) o la perspectiva desde la cual el productor presenta la imagen y posiciona al observador para su lectura. Esta dimensión codifica las relaciones entre el observador y los participantes representados mediante los ángulos frontal/oblicuo y alto/bajo. Los ángulos frontal y oblicuo pertenecen a la dimensión horizontal de la toma. Como sucede con la posición del cuerpo de las figuras, el ángulo frontal con el que se capta la imagen es el ángulo de mayor involucramiento y está orientado a la acción. Es decir, este ángulo comunica las ideas "this is how it works", "this is how you use it", "this is how you do it" (2006, p. 145). El ángulo frontal, pues, brinda un sentido de naturalismo e objetividad irrefutable. En contraste, cuando una imagen es captada desde un ángulo oblicuo la idea que se evoca es la de que esto no es parte de nuestro mundo, y las figuras que ahí aparecen no pertenecen a nuestro grupo, sino que son los “otros”, son “extraños” (2006, p. 138). La dimensión vertical en cambio, connota relaciones de poder (2006, p. 140). Cuando un participante es representado desde un ángulo alto (por ejemplo, el ángulo picado) el observador adquiere poder sobre este. Si en cambio, se coloca la mirada del observador en una posición inferior a la figura, es decir, si se toma o plasma desde un ángulo bajo, esta adquiere poder sobre el observador (como sucede en el ángulo contrapicado). Finalmente, si la figura se coloca al nivel de los ojos del observador, la relación que se establece entre ambos es de igualdad (2006, p. 140). 